\title{
The Embedded Majuscule
}

In a previous issue of the MRS BULLETIN (Vol. XII, No. 7, 1987, p. 100), we began Posterminaries with the observation that "language evolves." And indeed it does. A living lexicon with transforming usages adapts to our communication needs far better than would rigidity of syntax. Poetic license (of the truly literary variety), new objects or phenomena requiring names, and each generation's idioms of speech seem to have provided the main increments of language. But now new objects and poetic license (of a distinctly nonliterary kind) have conspired to give us the embedded majuscule-the uppercase letter smack-dab in the middle of a 'word.' We say word in inverted commas because, thank Webster, the insult has only cropped up in trade names and trademarks associated primarily with computer products. Some of the more notorious examples are LaserJet, PageMaker, PostScript, WordPerfect, WordStar, MultiMate, and MicroPro.' These all seem at least to be concatenations of individually respectable words. On the horizon however, following in the tradition of dBase, are such as XyQuest and ZSoft which can't even boast that. ${ }^{1}$

"Well," you say, "these are only proper names and surely newfangled products and their newfangled companies have every right to devise eye-catching, ear-charming symbols to tickle the buying public's fancy." Indeed so! Then what is the worry? It's simply that once ensconced in the gimmickry of trademarkery (or is that mockery?), who knows when these habits will leak into the unregistered, uncopyrighted everyday language, as have such venerable formerly proper nouns as kleenex, xerox, and frigidaire. And what will they mean? It is hard to predict when it will happen-but it most certainly will-and we should be ready by anticipating the greater utility this addition will provide.

To prepare we must assess the augmented meaning that these new forms will deliver. In the German language, where not only proper nouns and initial words of sentences are capitalized but all nouns are capitalized, compounding of words is the rule. Nevertheless, when internal to the compounds, those ubiquitous capitals drop to lower case. So the implication we seek must go beyond the mere juxtaposition of ideas. We propose it is the "bonding of coordinate species or ideas." Each component defends its independent and important identity by maintaining an initial upper-case letter while entering into a form of mutual association far more intimate than a mere solidus or hyphen could permit. A union of equals befitting the times. They are bonded as surely as the sodium and chlorine in $\mathrm{NaCl}$. We won't be surprised to find revisions as SolidState, HighEnergy, and NobelPrize creeping into Twenty First century technical texts while the general public welcomes the PostOffice's ExpressMail, the TaxCollector, and SpaceTravel. It will seem as natural as ApplePie.

E.N. KAUFMANN

1. Laserjet is a trademark of Hewlett Packard Corporation; PageMaker is a trademark of Aldus Corporation; PostScript is a trademark of Adobe Corporation; WordPerfect is a trademark of WordPerfect Corporation; MultiMate is a trademark of Multimate Corporation; WordStar and MicroPro are trademarks of MicroPro International Corporation; XyQuest is a trademark of XyQuest Corporation; ZSoft is a trademark of ZSoft Corporation $\mathrm{dBase}$ is a trademark of Ashton Tate Corporation.

\section{An Etch in Time Saves..... Philip H. Key University of Hull, United Kingdom}

If you want to do things proper,

When you're etching foils of copper,

Then an excimer's the laser you should use.

For a wavelength that is shorter,

Etches faster than it oughter,

When you only use the reds, or greens, or blues.

U.V. coupling is stronger,

Than the wavelengths that are longer,

And the etch rate is as good as any seen,

Patterns, sharper than a razor,

Near the focus of the laser,

And the plasma is a lovely shade of green.

If you want to do it faster,

Make an image, don't use raster,

And try to get the focusing just right.

With chlorine in the cell,

You will give that copper hell,

And remove a micron every single bite.
The chlorine, you will find,

To the copper is unkind,

It attacks the surface without hesitation,

Forming chlorides on the top,

At a rate you cannot stop,

Till you zap it and remove it by ablation.

There's a most important role,

For the fluence in the hole,

And a threshold you will see, so never fear,

Since the etch rate, you will find,

Follows closely on behind

A law that is attributed to Beer.

At high rep rates, it's sufficient,

To observe the coefficient

Of absorption, in the sample, will increase,

Thus the etch rate's getting slower,

But the fluence is not lower,

As the sample is ablated piece by piece.
Growth of a chloride layer,

On a surface we'd prepare,

Could be monitored by laser interf' rometry,

Looking in the right direction,

At the angle of reflection,

And application of the laws of trigonometry.

In preliminary stages,

You will find that you wait ages,

While the heli-neon probe beam settles down,

But your patience is rewarded,

When you find that you've recorded,

Results that bring to you that world renown.

When you're working late at night,

And there's nothing going right,

And you're cursing every problem that arises,

Do not give in to despair,

Just keep hoping, if you dare,

That someday this work will earn you Nobel Prizes. 